\title{
Reproductive parasitism in insects. The interaction of host and bacteria
}

\section{Irina Goryacheva and Boris Andrianov}

Laboratory of Insect Genetics, Vavilov Institute of General Genetics, Russian Academy of Sciences, ul. Gubkina, 3, Moscow, 117971, Russian Federation Department of General Biology and Bioecology, Moscow Region State University, ul. Very Voloschinoy, 24, Mytishchi, Moscow Region, 141014, Russian Federation

Address correspondence and requests for materials to Irina Goryacheva, iigoryacheva@mail.ru

\begin{abstract}
Reproductive parasitism is a specific form of symbiosis in which a microorganism alters the reproduction of the host by interfering with the mechanisms of sex development. The review considers four changes in reproduction - male killing, parthenogenesis, feminization, and cytoplasmic incompatibility - determined by cytoplasmic bacteria. The cytogenetic and molecular genetic mechanisms of interaction between partners in the symbiotic system are discussed, including the comparative analysis of molecular-genetic factors responsible for reproductive parasitism. The features of the interaction between an insect and bacteria in symbiosis with various systems for determining the sex of the host, male and female heterogamy and haplodiploidy, are considered. Studies of cytoplasmic incompatibility are of great practical importance, since they open up prospects for non-invasive engineering on natural insect populations for biocontrol.
\end{abstract}

Keywords: reproductive parasitism, male killing, parthenogenesis, feminization, cytoplasmic incompatibility, bacteria, insect

\section{Introduction}

Symbiotic bacteria can change the biology of infected insect species in many significant aspects. The most interesting type of relationship between an insect host and its symbiotic bacteria is reproductive parasitism. Symbiotic bacteria can cause cytoplasmic incompatibility in crosses of infected and bacteria-free insects, parthenogenesis, feminization of genetic males, or male killing (Fig. 1). All these effects increase the spread of symbiotic bacteria in the host populations and increase bacteria fitness, while symbiotic bacteria can have multidirectional effects on the fitness of the host insect. At the organismic level, symbiosis of an insect and intracellular symbiotic bacterium can be considered an antagonistic interaction between bacterium and insect, in which either the entire offspring of the host or the male offspring suffer (in the case of death of male embryos in the offspring of infected females). At the same time, at the population level, the consequences of reproductive parasitism can be assumed to be mutualistic. In populations infected with bacteria, the shift in the sex ratio towards females makes it possible to more quickly increase the population size, avoid inbreeding in the offspring, and effectively redistribute resources, providing the offspring of infected females with advantages in vitality and fitness.

The manifestation of all the noted reproductive effects caused by symbiotic bacteria critically depends on the chromosomal system of sex determination in insects. Chromosomal systems for determining sex in insects are diverse, even within the same order. The most widespread types are: chromosomal system $\mathrm{XX} / \mathrm{XY}$ (male heterogamety), chromosomal system XX/XO (male heterogamety
Citation: Goryacheva, I, and Andrianov, The interaction of host and bacteria. Bio. Comm. 66(1): 17-27. https://doi PhD, Head of Laboratory, Leading 5987; Boris Andrianov, Dr. of Sci. in Biology,

Manuscript Editor: Anton Nizhnikov, Department of Genetics and Biotechnolog

Received: September 21, 2020;

Revised: November 23, 2020;

Copyright: (c) 2021 Goryacheva and Andrianov. This is an open-access article distributed under the terms of the License Agreement with Saint Petersburg State University, which permits to the authors unrestricted distribution, and self-archiving free of charge.

Funding: This work was supported by a grant from the Russian Science Foundation 21 19-16-11013 (AGREEMENT No. 16-1600079-P).

Competing interests: The authors have declared that no competing interests exist. 


\section{Normal reproduction \\ Feminization Parthenogenesis Male killing \\ Cytoplasmic incompatibility
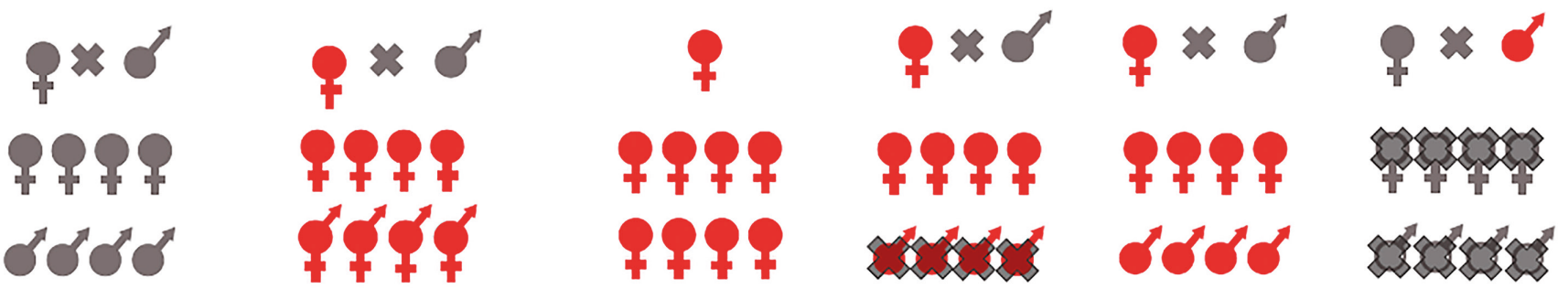

Fig. 1. Four types of reproductive parasitism - feminization, parthenogenesis, male killing and cytoplasmic incompatibility — determined by bacteria and normal sexual reproduction. Red — infected individual, grey — uninfected individual.

without Y-chromosome), chromosomal system ZW/ZZ or ZO/ZZ (female heterogamety), haplodiploidy (Sánchez, 2008). The molecular mechanism of parthenogenesis, feminization and male killing caused by a symbiotic bacterium is determined by the work of specific bacterial genes that disrupt the work of the gene cascade for determining the sex of the host insect. These genes are not an obligatory part of the bacterial genome; they are associated with mobile elements of the bacterial genome (Fukui et al. 2015; Harumoto and Lemaitre, 2018).

The ability to act as reproductive parasites has been revealed in bacteria from the genera Spiroplasma (Tenericutes) (Matsuka, Hashi and Okada, 1975), Wolbachia (a-Proteobacteria) (Yen and Barr, 1971; Stouthamer, Breeuwer and Hurst, 1999; Jiggins, Hurst and Majerus, 1998, 2000; Hurst et al., 1999; Narita, Kageyama, Nomura and Fukatsu, 2007), Rickettsia ( $\alpha$-Proteobacteria) (Werren et al., 1994; Adachi-Hagimori, Miura and Stouthamer, 2008), Arsenophonus ( $\gamma$-Proteobacteria) (Werren, Skinner and Huger, 1986), and Cardinium (Bacteroidetes) (Hunter, Perlman and Kelly, 2003; Zchori-Fein et al., 2004).

\section{Male killing}

Male killing was first described in Adalia bipunctata by Ya. Ya.Lus (Lus, 1947). Bacterial male killing is phenotypically manifested by the death of about half of the eggs in the clutch of infected females and a predominance of females in insect populations. Male killing has been reported for bacteria from the genera Spiroplasma, Rickettsia, Wolbachia and Arsenophonus (Matsuka, Hashi and Okada, 1975; Werren et al., 1994; Jiggins, Hurst and Majerus, 1998, 2000; Hurst et al., 1999; Werren, Skinner and Huger, 1986). The taxonomic status of insect species in which male killing has been reported is also diverse and include species with male and female heterogamy and haplodiploidy. The most significant progress in understanding the molecular mechanisms of male killing has been achieved in the study of two symbiotic systems: Drosophila melanogaster - Spiroplasma poulsonii and Ostrinia sp. - Wolbachia (Table 1).

The male killing phenomenon in Drosophila, caused by the presence of the symbiotic Spiroplasma, was described for the first time in the 1950s (Malo-

Table 1. Symbiotic systems of insects and bacteria with assumed molecular interaction mechanisms

\begin{tabular}{|c|c|c|c|c|c|c|}
\hline $\begin{array}{l}\text { Reproductive } \\
\text { phenotype }\end{array}$ & Insect Host & $\begin{array}{l}\text { Chromosomal } \\
\text { system for } \\
\text { determination } \\
\text { of the sex }\end{array}$ & $\begin{array}{l}\text { Symbiotic } \\
\text { bacterium }\end{array}$ & $\begin{array}{l}\text { Host molecular } \\
\text { target }\end{array}$ & $\begin{array}{l}\text { Bacterial gene/ } \\
\text { genes involved in } \\
\text { insect-bacterium } \\
\text { interaction }\end{array}$ & References \\
\hline \multirow{3}{*}{ Male killing } & D. melanogaster & $X X / X Y$ & Spiroplasma & \multirow{2}{*}{$\begin{array}{l}\text { Dosage } \\
\text { compensation } \\
\text { machinery }\end{array}$} & Spaid & $\begin{array}{l}\text { Harumoto and } \\
\text { Lemaitre, } 2018\end{array}$ \\
\hline & O. scapulalis & ZW/ZZ & Wolbachia & & Unknown & Fukui et al., 2015 \\
\hline & $\begin{array}{l}\text { D. innubila, } \\
\text { D. borealis, } \\
\text { D. bifasciata }\end{array}$ & $X X / X Y$ & Wolbachia & $\begin{array}{l}\text { Unknown } \\
\text { (probably dosage } \\
\text { compensation } \\
\text { machinery) }\end{array}$ & $w m k$ & $\begin{array}{l}\text { Perlmutter et al., } \\
2019\end{array}$ \\
\hline $\begin{array}{l}\text { Cytoplasmic } \\
\text { incompatibility }\end{array}$ & $\begin{array}{l}\text { D. melanogaster } \\
\text { C. pipiens }\end{array}$ & $X X / X Y$ & Wolbachia & Unknown & CifA and CifB & $\begin{array}{l}\text { Shropshire and } \\
\text { Bordenstein, } 2019\end{array}$ \\
\hline
\end{tabular}


golowkin. 1958; Williamson and Poulson, 1979). It was later found that Spiroplasma causes only partial male killing in the laboratory line of Drosophila melanogaster. In this case, about half of the sons from infected females survive. The presence of the Spaid gene (S. poulsonii androcidin) in the Spiroplasma genome was shown (Harumoto and Lemaitre, 2018). The Spaid gene was mapped to the putative plasmid and has no homologues in the genomes of other bacterial species causing male killing. The protein SPAID (1065 amino acids) contains ankyrin repeats and OTU (ovarian tumor) deubiquitinase region. The SPAID protein is probably excreted from the bacterium into the cytoplasm of the insect cell and functions as a regulatory protein. Using a transgenic expression system (GAL4/UAS), it was shown that expression of the Spaid gene leads to differential death of males, but does not affect females (Harumoto and Lemaitre, 2018). The Spaid gene in the line with an incomplete male killing has a deletion of $828 \mathrm{bp}$. As a result, the C-terminal hydrophobic region was lost in the mutant protein, which is probably necessary for the development of the male killing phenotype. The functional significance of other SPAID protein domains has been confirmed experimentally. Deletion of the ankyrin domain of the Spaid gene resulted in a complete loss of the male killing phenotype, although the gene product was found in the nucleus. Deletion of the OTU domain in the Spaid gene led to a change in the male killing phenotype. The death of males in transgenic lines occurred, but at a later stage of development (at the pupa stage, and not at the second larval stage). The authors suggest that ankyrin repeats interact with the MSL dose compensation compensatory complex or with histones, and the OTU domain promotes the localization of SPAID in the nucleus, since the SPAID protein in the absence of the OTU domain was not detected in the nucleus (Harumoto and Lemaitre, 2018).

In transgenic fly embryos expressing the Spaid gene, the same cytological defects are observed that are characteristic of male embryos of flies infected with Spiroplasma. These defects include abnormal apoptosis of embryonic epithelial cells, normally not subjected to apoptosis, and malformations of the nervous system (Tsuchiyama-Omura, Sakaguchi, Koga and Poulson, 1988; Martin, Chong and Ferree, 2013; Harumoto, Anbutsu and Fukatsu, 2014; Harumoto and Lemaitre, 2018). At the cellular level, S. poulsonii causes DNA damage and segregation defects of the male X chromosome. Expression of the Spaid gene is accompanied by the formation of chromosomal bridges and an irregular distribution of chromosomes, including the appearance of chromosome fragments in somatic cells. The effects of expression of the Spaid gene depend on interaction of the SPAID protein with the MSL dose compensation compensatory complex (MSL-1, MSL-2, MSL-3, MLE, and MOF) (Gilfillan, Dahlsveen and Becker, 2004). The expression of genes for dose compensation in D. melanogaster males is necessary to normalize the level of expression of genes localized on the X chromosome. Spiroplasma does not kill male embryos if they lack some of the MSL proteins, but it does kill transgenic females that express proteins of the MSL complex. A molecular target for Spiroplasma can be both the MSL complex itself and the chromatin modifications that are carried out with the participation of this complex.

Another well studied symbiotic system in which the male killing phenomenon was observed is the symbiosis of butterflies from the genus Ostrinia and the bacterium Wolbachia. The genetic basis for sex determination in Lepidoptera is female heterogamy (ZW/ZZ). The progeny of the moth O. scapulalis from females infected with Wolbachia have only female genotype (ZW) and female phenotype at the stage of imago. All embryos with the (ZZ) genotype die at the larval stage. After treatment of infected females with tetracycline at imago stage prior to oviposition, intersexes appear in some numbers and they turn out to be genetic males with (ZZ) genotype. These males have mosaic phenotype. Their wings have colored sectors characteristic both for males and females (Kageyama, Ohno, Hoshizaki and Ishikawa, 2003; Kageyama and Traut, 2004; Sakamoto, Kageyama, Hoshizaki and Ishikawa, 2007).

The influence of Wolbachia in O.scapulalis is revealed at the stage of alternative splicing of the Osdsx gene transcript (Sugimoto, et al. 2010). This gene is a component of the signaling pathway of the doublesex $(d s x)$ gene, which is responsible for sex determination. In uninfected insects, the type of splicing corresponds to their genotype. In all Wolbachia-infected individuals, regardless of their genetic sex (ZZ or ZW), the Osdsx transcript is spliced according to the female pattern, which is accompanied by feminization of genetic males (ZZ). In individuals cured of Wolbachia, splicing occurs in the male pattern, regardless of their genetic sex, which is accompanied by masculinization of genetic females (ZW). The conflict between the karyotype and the type of splicing of the Osdsx gene leads to death at the embryonic or larval stage (Sugimoto and Ishikawa, 2012).

Understanding of the molecular mechanisms underlying the switching of the splicing types in O.scapulalis under the influence of Wolbachia appeared only after the study of the sex determination system in another representative of the order Lepidoptera, the silkworm Bombyx mori. These studies were summarized in a review (Katsuma et al., 2018). B. mori gene Feminizer (Fem) is located on the W chromosome of females (Kiuchi, Koga, Kawamoto and Shoji, 2014). Feminizer encodes piRNA, a small (29 nucleotides) RNA that binds to the PIWI protein. The resulting complex cleaves mRNA of the masculinizing gene Masculinizer (Masc) 
linked to the $\mathrm{Z}$ chromosome, which encodes a protein necessary for both masculinization and gene dose compensation, which occurs by repression of $Z$ linked genes. Thus, in B. mori, the primary signal of sex determination is the interaction between two sex chromosomes, mediated by piRNA in the Fem - piRNA - Masc system. In the case of O.furnacalis, the OfMasc gene is the ortholog of the Masc gene (Fukui et al., 2015; Fukui et al., 2018) It is the OfMasc gene expression that is the target of Wolbachia. In O.furnacalis infected with Wolbachia, the amount of mRNA of the OfMasc gene decreases at the early embryonic stages of development, which leads to embryonic mortality in males due to the lack of dose compensation of the genes linked to the $\mathrm{Z}$ chromosome (Fukui et al., 2015). In 2019, it was suggested that the candidate for a genetic determinant of male killing could be the wmk phage gene WO Wolbachia (WO-mediated killing), which transgenically causes male death in early embryogenesis and typical cytological defects in D. melanogaster (Perlmutter et al., 2019).

Data for other symbiotic systems, which allow for different mechanisms of male killing induction in insects, are fragmented and usually limited to cytological studies. The study of the symbiosis of Nasonia vitripennis and Arsenophonous nasonia makes it possible to localize the effect of the Arsenophonous bacterium on the formation of centrosomes that are required for early embryonic development (Ferree et al., 2008). As a result, mitotic spindles are unorganized and embryonic developmental stopped at the early stage. The rescue of Arsenophonusinduced male lethality is achieved by fertilization with sperm bearing the paternal sex ratio factor (PSR). PSR bypasses the need for maternal centrosomes by allowing transmission of the sperm-derived centrosome into the egg. Drosophila bifasciata infected with Wolbachia demonstrates abnormal apoptosis and death of males at the stage of embryogenesis. Male-killing Wolbachia infection induces DNA damage and chromosome segregation defects such as chromatin bridges accompanied by abnormally tangled DNA of the dosage-compensated $\mathrm{X}$-chromosome in male embryos. Cytogenetic mechanisms of male killing induced by Wolbachia and Spiroplasma are similar in all studied Drosophila species, which all have the same sex determination system, male heterogamy and gene dose compensation by the type of overexpression (Bentley, Veneti, Heraty and Hurst, 2007; Harumoto, Anbutsu and Fukatsu, 2014; Harumoto, Anbutsu, Lemaitre and Fukatsu, 2016; Harumoto, Fukatsu and Lemaitre, 2018). Taking into account that Wolbachia and Spiroplasma belong to different bacterial groups, $a$-Proteobacteria and Mollicutes, respectively, it is likely that similar molecular mechanisms of male killing caused by these bacteria arose as a result of convergent evolution. The question of horizontal transfer of genes encoding the genetic determinants of reproduc- tive parasitism remains open until now. The question of horizontal gene transfer encoding the genetic determinants of reproductive parasitism between different bacteria remains open to date.

The consequence of male killing phenomena at the population level is the bias of sex ratio from 1:1 towards females. In some cases, this deviation can reach extreme values. In 2001, the population of Hypolimnas bolina from Samoa Island consisted of $99 \%$ females and only $1 \%$ males. All of them were infected with Wolbachia. This shift was accompanied by a significant decrease in the level of intrapopulation variability. One of the consequences of this female domination is that a large number of females in the population may remain unmated. Of Samoan H. bolina $50 \%$ of females were unmated, implying sperm limitation (Dyson and Hurst, 2004). This example is not unique. In another Lepidoptera, Acraea encedon in Makerere, Uganda, $94 \%$ of Wolbachia-infected females were virgins (Jiggins, Hurst and Majerus, 2000). In H. bolina, the extreme sex ratio was maintained for about 100 years (400 generations) (Dyson and Hurst, 2004). Further monitoring of this population revealed the rapid spread of the dominant suppression system linked to the 25 th chromosome in the period from 2001 to 2006 . In the presence of this dominant suppression factor some of the males infected with Wolbachia survive. The spread of this dominant suppression factor led to a rapid increase in the number of males, and at the end of this period they reached $50 \%$ of total population (Hornett et al., 2014). Earlier, the dominant autosomal factors suppressing the effect of male-killing bacteria were reported by Majerus and Majerus (2010). In the case of Cheilomenes sexmaculata a single dominant allele exists which rescues male progeny of infected females from the pathological effect of the male-killer. The gene shows typical Mendelian autosomal inheritance and is expressed irrespective of the parent from which it is inherited. A nuclear suppressor of a cytoplasmic male-killing Spiroplasma endosymbiont has spread rapidly in a population of the green lacewing Mallada desjardinsi (Hayashi, Nomura and Kageyama, 2018). Most of the offspring derived from individuals collected in 2016 had a 1:1 sex ratio in subsequent generations. Contrastingly, all-female or female-biased broods appeared frequently from crossings of these female offspring with males derived from a laboratory line founded by individuals collected in 2011 . These results suggest near-fixation of a nuclear suppressor against male killing in 2016 and reject the notion that a non-male-killing Spiroplasma variant has spread in the population. Consistently, no significant difference was detected in mitochondrial haplotype variation between 2011 and 2016. Thereby the quick events of male recovery occur more commonly than is generally appreciated. 


\section{Parthenogenesis}

Reproductive symbiotic bacteria are capable of inducing thelytoky parthenogenesis, in which females produce females without fertilization. One of the main biological advantages of thelytoky is the acceleration of the rate of reproduction and the possibility of a rapid increase in the population size. The recent case database includes 124 species from seven different arthropod taxa, including 54 confirmed cases and 70 suspected cases (Ma and Schwander, 2017). In most species that develop thelytoky under the influence of reproductive symbionts, sex is determined by haplo-diploidy, in which males develop from haploid unfertilized eggs, and females from diploid, fertilized eggs, but this database also includes diplo-diploid systems, in which sexual differentiation of offspring depends on the sex chromosomes in heterogametic sexes of males or females. The list of diploid insect species may be expanded in the near future. In 2020, a report appeared about the coccinellid Nephus voeltzkowi Weise, which reproduces parthenogenetically. The reasons for this phenotype remain unknown, but the parthenogenetic population is infected with Wolbachia, the association of which with parthenogenesis remains to be determined (Magro et al., 2020). The symbiontinduced parthenogenesis is most common in Hymenoptera (46 hymenopterans). In total, the frequency of parthenogenesis in Hymenoptera can be 15-30\% (Ma and Schwander, 2017).

In most of the studied insect species in which parthenogenesis caused by bacteria was confirmed Wolbachia was its cause (56\%). Less commonly, parthenogenesis is caused by Cardinium (13\%) and Rickettsia (4\%). According to Ma and Schwander (2017), the values for Wolbachia are overestimated and will decline in the future, as many studies have tested only Wolbachia and not other bacteria species. The principal cytological mechanism of thelytoky is the preservation or restoration of diploidy of oocytes. It should be noted that there is no apparent phylogenetic pattern with respect to which species uses which molecular mechanism of parthenogenesis, and closely related species may employ different mechanisms of parthenogenesis (Giorgini, Hunter, Mancini and Pedata, 2007).

The cytogenetic mechanisms underlying parthenogenesis have variable consequences on heterozygosity. The heterozygosity is maintained under mitotic and certain forms of meiotic parthenogenesis. In the case of mitotic parthenogenesis, offspring are genetically identical to their mother. Mitotic parthenogenesis has been described for wasps Neochrysocharis formosa and occurs under the influence of Rickettsia (Adachi-Hagimori, Miura and Stouthamer, 2008). In cases of parthenogenesis proceeding through the mechanisms of central or terminal fusion, recombinant variability is observed in the off- spring. Central fusion automixis has been described in the genus Encarsia and is induced by the bacterium Cardinium (Zchori-Fein et al., 2004; Giorgini, Hunter, Mancini and Pedata, 2007). Terminal fusion automixis has been described only for the wasp Aphytis metilaspidis, although the endosymbiont in this host is still unknown (Rössler and Debach, 1972, 1973). In most cases, parthenogenesis occurs as a result of gametic duplication. The cytological mechanisms of gametic duplication differ significantly among different insect species. In wasps of the genus Trichogramma: T.pretiosum, T.deion and T. nr. deion, as well as in the wasp Leptopilina clavipes, diploidization occurs due to the violation of segregation of two chromosome sets in the first division of meiosis (Stouthamer and Kazmer, 1994; Pannebakker, Pijnacker, Zwaan and Beukeboom, 2004). In the wasp Muscidifurax uniraptor, the normal first division of meiosis is followed by an abnormal second division, which ends with the fusion of haploid nuclei, with the restoration of diploidy (Gottlieb, Zchori-Fein, Werren and Karr, 2002).

Despite significant efforts, the molecular mechanisms of symbiotic bacteria-induced parthenogenesis remain unclear. In haplodiploid species, the endosymbiont is possibly capable of diploidizing unfertilized haploid eggs, which then develop into females (Heimpel and de Boer, 2008). In 2015, experimental data were obtained for Asobata tabida, which made it possible to formulate the original hypothesis of two-stage parthenogenesis, according to which the endosymbiont at first initiates diploidization and then triggers feminization. Both diploidization and feminization appear to be dependent on the bacterial density in the cell (Ma, Pannebakker, van de Zande and Schwander, 2015). This two-stage parthenogenesis occurs in at least two wasp species, T.kaykai and A. tabida (Tulgetske, 2010; Ma, Pannebakker, van de Zande and Schwander, 2015). However, an alternative mechanism is also possible, in which the bacterium feminizes the haploid eggs, which then diploidize under the influence of either this bacterium or the host, to avoid possible conflict between ploidy and the sex. The feminization mechanism followed by diploidization is possibly realized in the wasp E. hispida. In this case, females primarily infected with Cardinium, after treatment with antibiotics and elimination of the bacteria, produce offspring consisting of diploid males, although males in wasps are usually haploid (Giorgini et al., 2009). In this case, it is possible that Cardinium is not involved in the restoration of the diploid state. If the bacterium nevertheless restores diploidy, then the reproductive effect of Cardinium can be defined as the induction of parthenogenesis. If diploidy is restored not under the influence of Cardinium, then the reproductive effect of the bacterium is feminization in the strict sense. At the molecular level, the mechanisms of interaction between partners remain unclear. Genome sequencing of the Wolbachia 
wasp Trichogramma pretiosum did not reveal the specific genes responsible for the induction of thelytoky (Lindsey, Werren, Richards and Stouthamer, 2016). A comparative analysis of several genomes (29 genomes) of Wolbachia was also not informative in this regard (Lindsey, 2020).

\section{Feminization}

Feminization, or the transformation of genetic males into functional females, is a rare case in insects. Feminization has been described for two butterflies from the whitefly family - Eurema hecabe and E. mandarina (Lepidoptera: Pieridae) with female heterogamy - and for leafhoppers Zyginidia pullula with a sex determination system (XX / X0) (Hemiptera: Cicadellidae). In these three cases, feminization develops under the influence of Wolbachia (Hiroki, Tagami, Miura and Kato, 2004; Negri, Pellecchia and Mazzoglio, 2006; Narita, Kageyama, Nomura and Fukatsu, 2007; Narita, Nomura and Kageyama, 2007; Narita et al., 2011). Feminization may not be complete if exposure to the bacteria does not last for a long time. In this case, the result of feminization is the emergence of intersex (Narita, Kageyama, Nomura and Fukatsu, 2007). Cultivation of Wolbachia-infected larvae of E. mandarina on a medium with antibiotics results in many of the emerged imago displaying sexually intermediate traits in their wings, reproductive organs and genitalia. The age at which antibiotics were administered was found to be important, with the highest level of intermediate sexual traits being exhibited when first instar larvae were treated. Data on the cytological and molecular genetics mechanisms of feminization are scarce. In intersex Z.pullula, changes in methylation patterns are observed. The male pattern of methylation is associated with a reduced Wolbachia density, and the female methylation pattern is found in insects with a high Wolbachia density (Negri, Pellecchia and Mazzoglio, 2006; Negri et al., 2009). In E.mandarina, Wolbachia disrupts the inheritance of the female $\mathrm{Z}$ chromosome. Females with genotype Z0, infected with the Wolbachia line $w$ Fem, lay fertilized diploid eggs, which contain only one $\mathrm{Z}$ chromosome obtained from the father. Feminization in these $\mathrm{Z} 0$ embryos occurs according to a still unclear molecular mechanism. The female phenotype of infected embryos develops due to $d s x$ gene splicing according to female type. As a result, they produce only female progeny.

\section{Cytoplasmic incompatibility}

Cytoplasmic incompatibility (CI) is the most common change in insect reproductive strategy that occurs under the influence of reproductive symbiotic bacteria. CI can be observed in the progeny of males and females of a different infection status (i.e., infected and uninfected or both infected but with different symbiont strains) (Yen and Barr, 1971, 1973). In diploid species, CI is manifested in the death of offspring from parents with different infectious status. In haplo-diploid insect species, CI is manifested either in the death of offspring, or in the appearance of only males in the offspring from parents with different infectious status. CI was first described in Culex pipiens mosquitoes (Yen and Barr, 1971). Now CI is known among representatives of all orders of insects. Unlike male killing, feminization of genetic males and parthenogenesis, CI does not lead to a shift in the sex ratio in populations, but its biological meaning is the same as in other manifestations of reproductive bacteria parasitism. In the case of CI, the offspring not infected with the bacterium dies, which leads to the gradual spread of the reproductive bacteria in the insect population.

Bacteria of two genera, Wolbachia and Cardinium, are capable of inducing CI. The manifestations of CI arising under the influence of these bacteria are similar (Breeuwer and Werren, 1990; Gebiola et al., 2017). The cellular basis of the $\mathrm{CI}$ is disorders of the first division of the zygote. In embryos from dysgenic crosses, the asynchronous entry of maternal and paternal chromosomes into the first mitosis and abnormal segregation of chromosomes, accompanied by the appearance of chromosomal bridges with the subsequent formation of aneuploid nuclei, are observed (Breeuwer and Werren, 1990; Callaini, Dallai and Riparbelli, 1997; Tram, Fredrick, Werren and Sullivan, 2006). The asynchronous entry of parental chromosomal sets into the first mitosis is possible due to the unique feature of the insect division spindle, in which various microtubules interact with the paternal and maternal chromosomes. As a result, during normal development of the insect embryo, the chromosome sets obtained from the male and female in the first divisions of the cleavage of the nucleus of the zygote divide synchronously, but independently, and do not mix in metaphase and anaphase. The maternal chromosome set of embryos from dysgenic crosses successfully passes the stages of metaphase and anaphase, while the paternal chromosomes do not divide in metaphase or are separated with delay or incorrectly (Callaini, Dallai and Riparbelli, 1997; Tram, Fredrick, Werren and Sullivan, 2006; Gebiola et al., 2017). The similarity of cytological manifestations of CI determined by both symbionts suggests that, despite the significant phylogenetic distance separating Wolbachia and Cardinium, both bacteria have the same effect on the process of mitosis in the early development of embryos, possibly due to their ability to affect the same conservative molecular targets of their hosts (Penz, Schmitz-Esser, Kelly and Cass, 2012; Gebiola et al., 2017). Minor differences between the manifestations of CI in different cases relate to the moment of stopping the development of embryos. In the 
case of CI in Drosophila under the influence of Wolbachia, about $50 \%$ of embryos stop developing at the stage of early intravitelline mitoses; the remaining embryos stop developing either at the stage of syncytial blastoderm (about 6\%) or immediately before hatching (about $43 \%)$. In N. longicornis and N.giraulti, under the influence of Wolbachia, developmental arrest occurs after the first mitoses in $70 \%$ and $65 \%$ of embryos, respectively. In N.giraulti, about $30 \%$ of embryos reach the blastoderm stage, although their cells show signs of aneuploidy (Vavre, Dedeine, Quillon and Fouillet, 2001). However, in E. suzannae wasps, embryos infected with Cardinium die much later, just before hatching from eggs, probably due to the accumulation of defects that appeared in the first mitotic divisions (Gebiola et al., 2017).

Independent control of the transition from metaphase to anaphase of the maternal and paternal halves of the first mitotic spindle of division in insects explains the developmental features of CI in haplo-diploid and diploid insect species. In haplo-diploid species, with serious disturbances in the structure of the paternal chromatin after the first mitosis, only one nucleus, containing only maternal chromosomes, is morphologically normal. A normal haploid male develops from this nucleus. This type of CI has been described for N. vitripennis wasps. Incorrect segregation of the paternal chromatin into the nuclei of both blastocytes after the first mitosis leads to aneuploidy of both nuclei and, as a consequence, the death of the offspring at the embryonic stage. This type of CI is known for N.longicornis and N.giraulti wasps, as well as E. suzannae. In diploid insect species, such as C. pipiens mosquitoes, the haploid embryos that may appear in the case of CI are not viable, so total embryonic mortality is the result of $\mathrm{CI}$ in such species.

The molecular cause of the condensation defects of male chromosomes in insect embryos obtained from cytologically incompatible parents is the chromatin modification carried out by the bacterium. In formal genetic terms, the phenomenon of bacteria-modified male chromatin is designated as a hereditary factor (Mod) with a plus sign if modification takes place, or a minus sign if there is no modification. When mating (Mod +) males with uninfected females the progeny develops CI, but when mated with females infected with the same line of reproductive bacteria, the male factor $(\operatorname{Mod}+)$ is suppressed. In this case, the paternal chromosomes are completely condensed and normally diverge in anaphase, resulting in the appearance of viable embryos (Reed and Werren, 1995; Callaini, Dallai and Riparbelli, 1997; Tram, Fredrick, Werren and Sullivan, 2006). The hereditary factor by which the eggs of infected mothers suppress condensation defects in paternal chromatin is known as (Resc) with a plus sign if present, or minus if not. It is essential to emphasize that the factors (Mod) and (Resc) are specific not for the bacterial species, but for the bacterial lineage, which explains the wide variety of CI systems in nature. The modification-rescue model describes well many cases of Wolbachia-induced CIs (Zaba et al., 2008).

The discovery of the Wolbachia CI factors turned out to be a significant step in understanding the molecular mechanisms of this phenomenon (Beckmann and Fallon, 2013; Beckmann, Ronau and Hochstrasser, 2017; LePage et al., 2017; Shropshire et al., 2018). It has been shown that the induction of CI requires the activity of the two-gene operon (hereinafter in accordance with Beckmann et al., 2019), in which the genes can be designated as cif. Within each Cif pair, the protein encoded by the upstream gene is denoted $\mathrm{A}$ and the downstream gene $\mathrm{B}$. The term Cif is used to address all $\mathrm{CI}$ factors that is, CifA refers to any A protein in a CI operon, and $\mathrm{CifB}$ refers to the $\mathrm{B}$ proteins in $\mathrm{CI}$ operons. Operons can be classified into groups based on the enzymatic activity of group B proteins. Type I is a "cid" (CI-inducing deubiquitylase) operon that encodes a deubiquitylase (DUB); types II-IV are all "cin" operon variants that encode a nuclease (Beckmann, Ronau and Hochstrasser, 2017; Beckmann et al., 2019; Chen, Ronau, Beckmann and Hochstrasser, 2019). Several of the Type V operons encode $B$ proteins predicted to have both active nuclease and DUB domains (Beckmann et al., 2019; Bing et al., 2020). None of the CidA /CinA proteins have intrinsic enzymatic activity, although some sequences are similar to catalase, STE transcription factors or RNAbinding domains (Lindsey et al., 2018; Shropshire, On, Layton and Zhou, 2018; Beckmann et al., 2019). The Cifs are found as part of a "eukaryotic association module" (EAM) within a WO prophage (Beckmann et al., 2019).

The functional activity of Cif proteins was confirmed using transgenic systems. Postzygotic male sterility occurs under the influence of both CidB and CinB and manifests itself through interference with embryonic nuclear division (Beckmann, Ronau and Hochstrasser, 2017; LePage et al., 2017; Shropshire et al., 2018; Chen, Ronau, Beckmann and Hochstrasser, 2019). Defects arising in transgenic embryos are similar to the established developmental anomalies in CI: impaired male pronuclear chromatin condensation at metaphase and delayed chromosome separation and bridging at anaphase. Transgenic cidA ( $c i d A^{\mathrm{wMel}}$, cidA-cidB $\left.{ }^{w \mathrm{Mel}}\right)$ and $\operatorname{cin} A$ ( $\left.\operatorname{cin} A^{\omega \mathrm{Pip}}\right)$ female flies rescue these defects caused by Wolbachia-infected male flies (LePage et al., 2017; Shropshire et al., 2018; Chen, Ronau, Beckmann and Hochstrasser, 2019; Shropshire and Bordenstein, 2019. Operons ( $c i d A-c i d B$ and $\operatorname{cin} A-\operatorname{cin} B)$ demonstrate biochemically different mechanisms of CI. The predicted functional status of the enzymatic components of Coif operons correlates with the ability of diverse Wolbachia strains to induce bi-directional CI. A large-scale population genomic screen of Culex mosquitoes linked cross- 
ing-type diversity in CI among mosquitoes infected with different $w$ Pip strains to genetic variations in the cidA$c i d B^{\text {wPip }}$ operon (Bonneau et al., 2018, 2019).

The discovery of the factors of CI raised the issue of its molecular mechanisms, which are currently the subject of research. Based on data on the structure and functional characteristics of the $\operatorname{cid} A-c i d B$ operon, Beckmann et al. hypothesized about the molecular mechanism of CI induction and propose the "toxinantidote" model of CI (Beckmann et al., 2019). This hypothesis develops the previously stated "lock-andkey" hypothesis. In accordance with the toxin-antidote model both proteins, CidB (toxin) and CidA (antidote), are secreted by Wobachia into the sperm precursor cell through the use of a type IV secretion system. Proteins may not be secreted strictly stoichiometrically $1: 1$. The protein CidA is likely more abundant. A unique event in early fertilization (or late spermatogenesis), such as protamine replacement, can trigger targeted degradation or inactivation of $\mathrm{CidA}$, which activates the toxin. It can be assumed that if CidB is not neutralized in the zygote, it turns out to be toxic to developing embryos. CidA must be replenished by secretion or release in the infected germ line. It is possible that CidA degrades more rapidly than CidB, which is typical of bacterial toxin-antidote systems. Since the toxin is an enzyme, very little is needed to induce CI.

The developing spermatozoans are connected by a common cytoplasmic network formed by circular canals (Serbus, Casper-Lindley, Landmann and Sullivan, 2008), and CidB is apparently distributed in all haploid spermatozoans in an amount sufficient for the induction of CI. An additional amount of CidA and CidB proteins in the cytoplasm of developing spermatozoa is possible during lysis of bacterial cells induced by the WO phage.

Rescue can be a more complex process and require more components than the single protein CidA, which in turn can work in conjunction with other factors to counter the action of the deubiquitination enzyme (DUB) in the egg. However, rescue can be achieved alternatively by changing localization of the toxin, as well as by blocking the activity of its specific substrate. Modern research in general is developing within the framework of the toxin-antidote model. New genes are being identified, and their role in the symbiotic system is being clarified. The Two-By-One model was proposed by Shropshire et al. based on the results of a study of CI in D. melanogaster determined by Wolbachia (Shropshire et al., 2018; Shropshire and Bordenstein, 2019). According to the Two-by-One model of CI, two genes act as the CI modification factors (in the male), and one of these same genes acts as the rescue factor (in the female).This modification-rescue model posits that each strain of Wolbachia has its own set of cifA- and cifB-associated CI modifications and one cifA rescue factor. The function of cifA is dependent on differential localization and/or modification of gene products in testes/sperm (CI) relative to ovaries/embryos (rescue).

Further studies of cytoplasmic incompatibility are of great practical importance, since they open up the prospects for non-invasive engineering on natural insect populations to replace dangerous forms of insects - vectors of disease - with harmless ecologically vicarious forms, which in the future will make it possible to abandon the massive use of chemical insect control agents.

\section{Conclusion}

Reproductive parasitism is a symbiotic system of interaction between insects and bacteria. The data obtained so far suggests that in different groups of bacteria capable of modifying insect reproduction, the mechanisms for manipulating the host's reproduction have emerged convergently and independently. However, the problem of horizontal transfer between different bacteria of genes encoding the genetic determinants of reproductive parasitism is not resolved to date. Identifying and comparing molecular genetic mechanisms of interactions is an important area of future work.

\section{Reference}

Adachi-Hagimori, T., Miura, K., and Stouthamer, R. 2008. A new cytogenetic mechanism for bacterial endosymbiont-induced parthenogenesis in Hymenoptera. Proceedings of the Royal Society B: Biological Sciences 275:26672673. https://doi.org/10.1098/rspb.2008.0792

Beckmann, J. F., Bonneau, M., Chen, H., Hochstrasser, M., Poinsot, D., Mercot, H., Weill, M., Sicard, M., and Charlat, S. 2019. The toxin-antidote model of cytoplasmic incompatibility: Genetics and evolutionary implications. Trends in Genetics 35:175-185. https://doi.org/10.1016/j. tig.2018.12.004

Beckmann, J. F. and Fallon, A. M. 2013. Detection of the Wolbachia protein WPIP0282 in mosquito spermathecae: Implications for cytoplasmic incompatibility. Insect Biochemistry and Molecular Biology 43:867-878. https://doi. org/10.1016/j.ibmb.2013.07.002

Beckmann, J., F., Ronau, J. A., and Hochstrasser, M., A. 2017. A Wolbachia deubiquitylating enzyme induces cytoplasmic incompatibility. Nature Microbiology 2:17007. https:// doi.org/10.1038/nmicrobiol.2017.7

Beckmann, J. F., Sharma, G.D., Mendez, L., Chen, H., and Hochstrasser, M. 2019. The Wolbachia cytoplasmic incompatibility enzyme CidB targets nuclear import and protamine-histone exchange factors. elife 8:e50026. https://doi.org/10.7554/eLife.50026

Bentley, J. K., Veneti, Z., Heraty, J., and Hurst, G. D. D. 2007. The pathology of embryo death caused by the male-killing Spiroplasma bacterium in Drosophila nebulosa. BMC Biology 5:9 https://doi.org/10.1186/1741-7007-5-9

Bing, X. L., Zhao, D. S., Sun, J.T., Zhang, K. J., and Hong, X. Y. 2020. Genomic analysis of Wolbachia from Laodelphax striatellus (Delphacidae, Hemiptera) reveals insights into its "Jekyll and Hyde" mode of infection pattern. Genome Biology and Evolution 12:3818-3831. https://doi. org/10.1093/gbe/evaa006 
Bonneau, M., Atyame, C., Beji, M., Justy, F., Cohen-Gonsaud, M., Sicard, M., and Weill, M. 2018. Culex pipiens crossing type diversity is governed by an amplified and polymorphic operon of Wolbachia. Nature Communications 9:319. https://doi.org/10.1038/s41467-017-02749-w

Bonneau, M., Caputo, B., Ligier, A., Caparros, R., Unal, S., Perriat-Sanguinet, M., Arnoldi, D., Sicard, M., and Weill, M. 2019. Variation in Wolbachia cidB gene, but not cidA, is associated with cytoplasmic incompatibility mod phenotype diversity in Culex pipiens. Molecular Ecology 28:4725-4736. https://doi.org/10.1111/mec.15252

Breeuwer, J. A. and Werren, J. H. 1990. Microorganisms associated with chromosome destruction and reproductive isolation between insect species. Nature 346:558-560. https://doi.org/10.1038/346558a0

Callaini, G., Dallai, R., and Riparbelli, M. G. 1997. Wolbachiainduced delay of paternal chromatin condensation does not prevent maternal chromosomes from entering anaphase in incompatible crosses of Drosophila simulans. Journal of Cell Science 110(2):271-280.

Chen, H., Ronau, J. A., Beckmann, J. F., and Hochstrasser, M. A. 2019. Wolbachia nuclease and its binding partner provide a distinct mechanism for cytoplasmic incompatibility. Proceedings of the National Academy of Sciences USA 116:22314-22321. https://doi.org/10.1073/ pnas.1914571116

Dyson, E. A. and Hurst, G. D. D. 2004. Persistence of an extreme sex ratio bias in a natural population. Proceedings of the National Academy of Sciences USA 101(17):65206523. https://doi.org/10.1073/pnas.0304068101

Ferree, P. M., Avery, A., Azpurua, J., Wilkes T., and Werren J. H. 2008. A bacterium targets maternally inherited centrosomes to kill males in Nasonia. Current Biology 18(18):1409-1414. https://doi.org/10.1016/j. cub.2008.07.093

Fukui, T., Kawamoto, M., Shoji, K., Kiuchi, T., Sugano, S., Shimada, T., Suzuki, Y., and Katsuma, S. 2015. The endosymbiotic bacterium Wolbachia selectively kills male hosts by targeting the masculinizing gene. PLOS Pathogens 11(7):e1005048. https://doi.org/10.1371/journal. ppat.1005048

Fukui, T., Kiuchi, T., Shoji, K., Kawamoto, M., Shimada, T., and Katsuma, S. 2018. In vivo masculinizing function of the Ostrinia furnacalis Masculinizer gene. Biochemical and Biophysical Research Communications 503(3):1768-1772. https://doi.org/10.1016/j.bbrc.2018.07.111

Gebiola, M., Giorgini, M., Kelly, S.E., Doremus, M. R., Ferree, P. M., Hunter, M.S. 2017. Cytological analysis of cytoplasmic incompatibility induced by Cardinium suggests convergent evolution with its distant cousin Wolbachia. Proceedings of the Royal Society B: Biological Sciences 284:20171433. https://doi.org/10.1098/rspb.2017.1433

Gilfillan, G. D., Dahlsveen, I. K., and Becker, P. B. 2004. Lifting a chromosome: dosage compensation in Drosophila melanogaster. FEBS Letters 567:8-14. https://doi.org/10.1016/j. febslet.2004.03.110

Giorgini, M., Bernardo, U., Monti, M. M., Nappo, A. G., and Gebiola, M. 2010. Rickettsia symbionts cause parthenogenetic reproduction in the parasitoid wasp Pnigalio soemius (Hymenoptera: Eulophidae). Applied and Environmental Microbiology 76(8):2589-2599. https://doi. org/10.1128/AEM.03154-09

Giorgini, M., Hunter, M. S., Mancini, D., and Pedata, P. A. 2007. Cytological evidence for two different mechanisms of the thelytokous parthenogenesis in Encarsia parasitoids harbouring Wolbachia or Cardinium bacteria. X European Workshop on Insect Parasitoids. https://doi. org/10.13140/RG.2.1.4712.4243
Giorgini, M., Monti, M., Caprio, E., Stouthamer, R., and Hunter, M. S. 2009. Feminization and the collapse of haplodiploidy in an asexual parasitoid wasp harboring the bacterial symbiont Cardinium. Heredity 10:365-371. https://doi.org/10.1038/hdy.2008.135

Gottlieb, Y., Zchori-Fein, E., Werren, J. H., and Karr, T. L. 2002. Diploidy restoration in Wolbachia-infected Muscidifurax uniraptor (Hymenoptera: Pteromalidae). Journal of Invertebrate Pathology 81:166-174. https://doi.org/10.1016/ S0022-2011(02)00149-0

Harumoto, T., Anbutsu, H., and Fukatsu, T. 2014. Male-killing Spiroplasma induces sex-specific cell death via host apoptotic pathway. PLOS Pathogens 10(2):e1003956. https://doi.org/10.1371/journal.ppat.1003956

Harumoto, T., Anbutsu, H., Lemaitre, B., Fukatsu, T. 2016. Male-killing symbiont damages host's dosagecompensated sex chromosome to induce embryonic apoptosis. Nature Communications 7:12781. https://doi. org/10.1038/ncomms12781

Harumoto, T. and Lemaitre, B. 2018. Male-killing toxin in a bacterial symbiont of Drosophila. Nature 557:252-255. https://doi.org/10.1038/s41586-018-0086-2

Harumoto, T., Fukatsu, T., and Lemaitre, B. 2018. Common and unique strategies of male killing evolved in two distinct Drosophila symbionts. Proceedings of the Royal Society B: Biological Sciences 285(1875):20172167. https://doi. org/10.1098/rspb.2017.2167

Hayashi, M., Nomura, M., and Kageyama, D. 2018. Rapid comeback of males: evolution of male-killer suppression in a green lacewing population. Proceedings of the Royal Society B: Biological Sciences 285:20180369. https://doi. org/10.1098/rspb.2018.0369

Heimpel, G.E. and de Boer, J.G. 2008. Sex determination in the Hymenoptera. Annual Review of Entomology 53:209-230. https://doi.org/10.1146/annurev. ento.53.103106.093441

Hiroki, M., Tagami, Y., Miura, K., and Kato, Y. 2004. Multiple infection with Wolbachia inducing different reproductive manipulations in the butterfly Eurema hecabe. Proceedings of the Royal Society B: Biological Sciences 271:17511755. https://doi.org/10.1098/rspb.2004.2769

Hornett, E. A., Moran, B., Reynolds, L. A., Charlat, S., Tazzyman, S., Wedell, N., Jiggins, C.D., and Hurst, G.D.D. 2014. The evolution of sex ratio distorter suppression affects a $25 \mathrm{cM}$ genomic region in the butterfly Hypolimnas bolina. PLOS Genetics 10(12):e1004822. https://doi. org/10.1371/journal.pgen.1004822

Hunter, M. S., Perlman, S. J., and Kelly, S. E. 2003. A bacterial symbiont in the Bacteroidetes induces cytoplasmic incompatibility in the parasitoid wasp Encarsia pergandiella. Proceedings of the Royal Society B: Biological Sciences 270:2185-2190. https://doi.org/10.1098/rspb.2003.2475

Hurst, G.D. D., Jiggins, F. M., von der Schulenburg, J. H. G., Bertrand, D., West, S. A., Goriacheva, I. I., Zakharov, I. A., Werren, J. H., Stouthamer, R., and Majerus, M. E. N. 1999. Male-killing Wolbachia in two species of insect. Proceedings of the Royal Society B: Biological Sciences 266:735740. https://doi.org/10.1098/rspb.1999.0698

Jiggins, F., Hurst, G., and Majerus, M. 1998. Sex ratio distortion in Acraea encedon (Lepidoptera: Nymphalidae) is caused by a male-killing bacterium. Heredity 81:87-91. https:// doi.org/10.1046/j.1365-2540.1998.00357.x

Jiggins, F. M., Hurst, G.D., and Majerus, M. E. 2000. Sex-ratio-distorting Wolbachia causes sex-role reversal in its butterfly host. Proceedings of the Royal Society B: Biological Sciences 267(1438):69-73. https://doi.org/10.1098/ rspb.2000.0968 
Kageyama, D., Ohno, S., Hoshizaki, S., and Ishikawa, Y. 2003. Sexual mosaics induced by tetracycline treatment in the Wolbachia-infected adzuki bean borer, Ostrinias capulalis. Genome 46:983-989. https://doi.org/10.1139/g03-082

Kageyama, D., Ohno, M., Sasaki, T., Yoshido, A., Konagaya, T., Jouraku, A., Kuwazaki, S., Kanamori, H., Katayose, Y., Narita, S., Miyata, M., Riegler, M., and Sahara, K. 2017. Feminizing Wolbachia endosymbiont disrupts maternal sex chromosome inheritance in a butterfly species. Evolution Letters 1(5):232-244. https://doi.org/10.1002/evl3.28

Kageyama, D. and Traut, W. 2004. Opposite sex-specific effects of Wolbachia and interference with the sex determination of its host Ostrinias capulalis. Proceedings of the Royal Society B: Biological Sciences 271:251-258. https:// doi.org/10.1098/rspb.2003.2604

Katsuma, S., Kiuchi, T., Kawamoto, M., Fujimoto T, Sahara K. 2018. Unique sex determination system in the silkworm, Bombyx mori: current status and beyond. Proceedings of the Japan Academy, Series B 94(5):205-216. https://doi. org/10.2183/pjab.94.014

Kiuchi, T., Koga, H., Kawamoto, M., Shoji, K., Sakai, H., Arai, Y., Ishihara, G., Kawaoka, S., Sugano, S., Shimada, T., Suzuki, Y., Suzuki, M. G., and Katsuma, S. 2014. A single female-specific piRNA is the primary determiner of sex in the silkworm. Nature 509:633-636. https://doi. org/10.1038/nature13315

LePage, D.P., Metcalf, J. A., Bordenstein, S. R., On, J., Perlmutter, J. I., Shropshire, J. D., Layton, E. M., Funkhouser-Jones, L.J., Beckmann, J. F., and Bordenstein, S.R. 2017. Prophage WO genes recapitulate and enhance Wolbachia-induced cytoplasmic incompatibility. Nature 543:243-247. https://doi.org/10.1038/nature21391

Lindsey, A. 2020. Sensing, signaling, and secretion: A review and analysis of systems for regulating host interaction in Wolbachia. Genes 11(7):813. https://doi.org/10.3390/ genes11070813

Lindsey, A. R., Werren, J. H., Richards, S., and Stouthamer, R. 2016. Comparative genomics of a parthenogenesis-inducing Wolbachia symbiont. G3 Genes |Genomes | Genetics 6(7):2113-2123. https://doi.org/10.1534/g3.116.028449

Lus, Ya. Ya. 1947. Some trends in reproduction of the Adalia bipunctata L. populations: maleless lines in populations. Doklady Akademii Nauk SSSR 57(9):951-954. (In Russian)

Ma, W. J., Pannebakker, B. A., van de Zande, L., Schwander, T, Wertheim, B., and Beukeboom, L.W. 2015. Diploid males support a two-step mechanism of endosymbiont-induced thelytoky in a parasitoid wasp. BMC Evolutionary Biology 15:84. https://doi.org/10.1186/s12862015-0370-9

Ma, W. J. and Schwander, T. 2017. Patterns and mechanisms in instances of endosymbiont-induced parthenogenesis. Journal of Evolutionary Biology 30(5):868-888. https://doi. org/10.1111/jeb.13069

Magro, A., Lecompte, E., Hemptinne, J. L., Soares, A. O., Dutrillaux, A. M., Murienne, J, Fürsch, H, and Dutrillaux, B. 2020. First case of parthenogenesis in ladybirds (Coleoptera: Coccinellidae) suggests new mechanisms for the evolution of asexual reproduction. Journal of Zoological Systematics and Evolutionary Research 58:194-208. https://doi.org/10.1111/jzs.12339

Majerus, T.M. O. and Majerus, M. E. N. 2010. Intergenomic arms races: detection of a nuclear rescue gene of malekilling in a ladybird. PLOS Pathogens 6(7):e1000987. https://doi.org/10.1371/journal.ppat.1000987

Malogolowkin, C. 1958. Maternally inherited "sex-ratio" conditions in Drosophila willistoni and Drosophila paulistorum. Genetics 43(2):274-286. https://doi.org/10.1093/genetics/43.2.274
Martin, J., Chong, T., and Ferree, P. M. 2013. Male killing Spiroplasma preferentially disrupts neural development in the Drosophila melanogaster embryo. PLoS One 8(11):e79368. https://doi.org/10.1371/journal.pone.0079368

Matsuka, M., Hashi, H., and Okada, I. 1975. Abnormal sex-ratio found in the ladybeetle, Harmonia axyridis Pallas (Coleoptera: Coccinellidae). Applied Entomology and Zoology 10(2):84-89. https://doi.org/10.1303/aez.10.84

Narita, S., Kageyama, D., Nomura, M., and Fukatsu, T. 2007. Unexpected mechanism of symbiont-induced reversal of insect sex: feminizing Wolbachia continuously acts on the butterfly Eurema hecabe during larval development. Applied and Environmental Microbiology 3:4332-4341. https://doi.org/10.1128/AEM. 00145-07

Narita, S., Kageyama, D., Hiroki, M., Sanpei, T., Hashimoto, S., Kamitoh, T., and Kato, Y. 2011. Wolbachia-induced feminization newly found in Eurema hecabe, a sibling species of Eurema mandarina (Lepidoptera: Pieridae). Ecological Entomology 36:309-317. https://doi.org/10.1111/j.13652311.2011.01274.x

Narita, S., Nomura, M., and Kageyama, D. 2007. Naturally occurring single and double infection with Wolbachia strains in the butterfly Eurema hecabe: transmission efficiencies and population density dynamics of each Wolbachia strain. FEMS Microbiology Ecology 61:235-245. https://doi.org/10.1111/j.1574-6941.2007.00333.x

Negri, I., Franchini, A., Gonella, E., Daffonchio, D., Mazzoglio, P.J., Mandrioli, M., and Alma, A. 2009. Unravelling the Wolbachia evolutionary role: the reprogramming of the host genomic imprinting. Proceedings of the Royal Society B: Biological Sciences 276:2485-2491. https://doi. org/10.1098/rspb.2009.0324

Negri, I., Pellecchia, M., and Mazzoglio, P.J. 2006. Feminizing Wolbachia in Zyginidia pullula (Insecta, Hemiptera), a leafhopper with an XX/XO sex-determination system. Proceedings of the Royal Society B: Biological Sciences 273:2409-2416. https://doi.org/10.1098/rspb.2006.3592

Pannebakker, B.A., Pijnacker, L.P., Zwaan, B.J., and Beukeboom, L. W. 2004. Cytology of Wolbachia-induced parthenogenesis in Leptopilina clavipes (Hymenoptera: Figitidae). Genome 303:299-303. https://doi.org/10.1139/ g03-137

Penz, T., Schmitz-Esser, S., Kelly, S. E., Cass, B. N., Müller, A., Woyke, T., Malfatti, S.A., Hunter, M.S., and Horn, M. 2012. Comparative genomics suggests an independent origin of cytoplasmic incompatibility in Cardinium hertigii. PLOS Genetics 8(10):e1003012. https://doi.org/10.1371/ journal.pgen.1003012

Perlmutter, J.I., Bordenstein, S. R., Unckless, R. L., LePage, D. P., Metcalf, J. A., Hill, T., Martinez, J., Jiggins F. M., and Bordenstein, S. R. 2019. The phage gene wmk is a candidate for male killing by a bacterial endosymbiont. PLOS Pathogens 15(9):e1007936. https://doi.org/10.1371/ journal.ppat.1007936

Reed, K. M. and Werren, J.H. 1995. Induction of paternal genome loss by the paternal-sex-ratio chromosome and cytoplasmic incompatibility bacteria (Wolbachia): a comparative study of early embryonic events. Molecular Reproduction and Development 40:408-418. https://doi. org/10.1002/mrd.1080400404

Rössler, Y. and Debach, P. 1972. The biosystematics relations between a thelytokous and an arrhenotokous form of Aphytis mytilaspidis (LeBaron) [Hymenoptera: Aphelinidae]. Entomophaga 17:425-435. https://doi.org/10.1007/ BF02371647

Rössler, Y. and Debach, P. 1973. Genetic variability in athelytokous form of Aphytis mytilaspidis (LeBaron) (Hyme- 
noptera: Aphelinidae). Hilgardia 42:149-176. https://doi. org/10.3733/hilg.v42n05p149

Sakamoto, H., Kageyama, D., Hoshizaki, S., and Ishikawa, Y. 2007. Sex-specific death in the Asian corn borer moth (Ostrinia furnacalis) infected with Wolbachia occurs across larval development. Genome 50:645-652. https:// doi.org/10.1139/g07-041

Sánchez, L. 2008. Sex-determining mechanisms in insect. International Journal of Developmental Biology 52:837-856. https://doi.org/10.1387/ijdb.072396ls

Serbus, L. R., Casper-Lindley, C., Landmann, F., and Sullivan, W. 2008. The genetics and cell biology of Wolbachia - host interactions. Annual Review of Genetics 42:683-707. https:// doi.org/10.1146/annurev.genet.41.110306.130354

Shropshire, J.D. and Bordenstein, S. R. 2019. Two-By-One model of cytoplasmic incompatibility: Synthetic recapitulation by transgenic expression of cifA and cifB in Drosophila. PLOS Genetics 15:e1008221. https://doi. org/10.1371/journal.pgen.1008221

Shropshire, J.D, On, J., Layton, E. M., Zhou H., and Bordenstein, S. R. 2018. One prophage WO gene rescues cytoplasmic incompatibility in Drosophila melanogaster. Proceedings of the National Academy of Sciences USA 115:49874991. https://doi.org/10.1073/pnas.1800650115

Stouthamer, R., Breeuwer, J.A. J., and Hurst, G.D.D. 1999. Wolbachia pipientis: Microbial manipulator of arthropod reproduction. Annual Review of Microbiology 53:71-102. https://doi.org/10.1146/annurev.micro.53.1.71

Stouthamer, R. and Kazmer, D. 1994. Cytogenetics of microbeassociated parthenogenesis and its consequences for gene flow in Trichogramma wasps. Heredity 73:317-327. https://doi.org/10.1038/hdy.1994.139

Sugimoto, T. N., Fujii, T., Kayukawa, T., Sakamoto, H., and Ishikawa, Y. 2010. Expression of a double sex homologue is altered in sexual mosaics of Ostrinia scapulalis moths infected with Wolbachia. Insect Biochemistry and Molecular Biology 40:847-854. https://doi.org/10.1016/j. ibmb.2010.08.004

Sugimoto, T. N. and Ishikawa, Y. 2012. A male-killing Wolbachia carries a feminizing factor and is associated with degradation of the sex-determining system of its host. Biology Letters 8:412-415. https://doi.org/10.1098/ rsbl.2011.1114

Tulgetske, G. M. 2010. Investigations into the mechanisms of Wolbachia-induced parthenogenesis and sex determination in the parasitoid wasp, Trichogramma, PhD the- sis, Riverside, CA, Merritt. https://escholarship.org/uc/ item/52w0b481

Tram, U., Fredrick, K., Werren, J. H., and Sullivan, W. 2006. Paternal chromosome segregation during the first mitotic division determines Wolbachia-induced cytoplasmic incompatibility phenotype. Journal of Cell Science 119:3655-3663. https://doi.org/10.1242/jcs.03095

Tsuchiyama-Omura, S., Sakaguchi, B., Koga, K., and Poulson, D. F. 1988. Morphological features of embryogenesis in Drosophila melanogaster infected with a male-killing Spiroplasma. Zoological Science 5:375-383.

Vavre, F., Dedeine, F., Quillon, M., Fouillet, P., Fleury, F., and Boulétreau, M. 2001. Within-species diversity of Wolbachia-induced cytoplasmic incompatibility in haplodiploid insects. Evolution 55:1710-1714. https://doi. org/10.1111/j.0014-3820

Werren, J.H., Hurst, G.D.D., Zhang, W., Breeuwer, J.A., Stouthamer, R., and Majerus, M. E. 1994. Rickettsial relative associated with male killing in the ladybird beetle (Adalia bipunctata). Journal of Bacteriology 176:388-394. https://doi.org/10.1128/jb.176.2.388-394.1994

Werren, J.H., Skinner, S.W., and Huger, A. M. 1986. Malekilling bacteria in a parasitic wasp. Science 231:990-992. https://doi.org/10.1126/science.3945814

Williamson, D. L. and Poulson, D. F. 1979. Plant and insect mycoplasmas; pp. 175-208 in Whitcomb, R. F. and Tully, J. G. (Eds.), The Mycoplasmas. New York. https://doi. org/10.1016/B978-0-12-078403-5.50012-8

Yen, J. H. and Barr, A. R. 1971. New hypothesis of the cause of cytoplasmic incompatibility in Culex pipiens L. Nature 232:657-658. https://doi.org/10.1038/232657a0

Yen, J.H. and Barr, A.R. 1973. The etiological agent of cytoplasmic incompatibility in Culex pipiens. Journal of Invertebrate Pathology 22(2):242-250. https://doi. org/10.1016/0022-2011(73)90141-9

Zabalou, S., Apostolaki, A., Pattas, S., Veneti, Z., Paraskevopoulos, Ch., Livadaras, I., Markakis, G., Brissac, T., Merçot, H., and Bourtzis, K. 2008. Multiple rescue factors within a Wolbachia strain. Genetics 178:2145-2160. https://doi. org/10.1534/genetics.107.086488

Zchori-Fein, E., Perlman, S. J., Kelly, S. E., Katzir, N., and Hunter, M. S. 2004. Characterization of a 'Bacteroidetes' symbiont in Encarsia wasps (Hymenoptera: Aphelinidae): proposal of 'Candidatus Cardinium hertigii'. International Journal of Systematic and Evolutionary Microbiology 54(3):961-968. https://doi.org/10.1099/ijs.0.02957-0 